\title{
Comparative analysis of the application of educational technologies for sustainable development
}

\author{
Lyudmila I. Sokolova*, and Dmitry S. Ermakov \\ Peoples' Friendship University of Russia (RUDN University), Department of Psychology and \\ Pedagogy, 117198, 6 Miklukho-Maklaya Street, Moscow, Russia
}

\begin{abstract}
It must be admitted that education is the necessary requirement, and educational technologies are the important tools of implementation for sustainable development. This study is based on a comparative and pedagogical approach. Having used the content analysis method we have considered the data of national reports (2018) from 31 countries on implementing the Strategy of education for sustainable development (ESD) of UNECE (sub-indicator 2.1.3) and defined pedagogical technologies applied at different levels of formal, non-formal and informal education. Besides, the rating of technologies according to the frequency of their usage for $0-8$ levels has been made. The revealed differences we explain by age-related psychological features of students and pupils, as well as the national peculiarities of educational systems. Moreover, a brief overview about additional educational technologies and methods that are outside the framework of the current ones (non-formal and informal education in particular) has been prepared. The results of experts' survey in Russian Federation carried out in 2019 have been introduced. The general evaluation of progress in the field of ESD with the 3-point scale $(0.7$; in progress) and estimation of indicator 2.1 (0.9; in progress) has been defined. We also characterised the revealed educational-methodical achievements.
\end{abstract}

\section{Introduction}

It is a common understanding that education has been recognized as the indispensable condition and an important tool of implementation for sustainable development [1]. The quality and accessibility of education (Sustainable development goal № 4) are largely defined by the applied pedagogical technologies [2]. They include the system of training forms, methods and approaches that insure the most efficient achievement of setting goals.

To bring to the attention of the students the global values for sustainable world (diversity, respect for civic freedoms, gender equality, the urgency of combatting climate change, etc.) it is necessary for educators to master a wide range of appropriate actual teaching and learning methods that must be actively used in the educational process [3].

\footnotetext{
* Corresponding author: 1sokolova777@mail.ru
} 


\section{Research Methods}

We have previously analysed the national implementation reports of the United Nations Economic Commission for Europe (UNECE) Strategy for education for sustainable development (ESD) from 37 countries (phase III, 2011-2015). According to the analysis, the Pedagogical technologies used for an implementation of UNECE Strategy for ESD in the levels of formal, non-formal and informal education have been revealed and classified (traditional, project, interactive, information and communication technologies). The main pedagogical technologies in ESD have been defined and ranked according to the frequency of their application in different countries and at different levels of education [4].

The results of the similar study of the national implementation reports from 31 countries (2018) are introduced in this article [5]. Having analysed data of sub-indicator 2.1.3 "Are teaching / learning methods that support ESD addressed explicitly in the curriculum / programme of study at various levels of formal education?") we defined the appropriate teaching technologies/methods that support ESD (abbreviation is given further in the brackets): case studies (CS), conceptual and perceptual mapping (M), discussions (D), excursions and outdoor learning (OL), good practice analyses (GP), information and communicative technologies (I), learner-driven projects $(\mathrm{P})$, philosophical inquiry (PI), problem-solving (PS); scenarios, modelling (SM); simulations, role playing, games $(\mathrm{G})$; surveys (S), value clarification (VC), workplace experience (WE).

In order to get the complete assessment of the ESD advance, the survey of experts who are known as the specialists in the field of ESD was carried out in 2019. The same sub-indicator and 3point scale were used in accordance with the national implementation reports.

\section{Findings}

The main teaching and learning methods that support ESD at various levels of formal education are presented in Table 1 (in accordance with International standard classification of education ISCED 2011) [6]: 0. Early childhood education; 1. Primary education; 2. Lower secondary education; 25. Lower secondary vocational education; 3. Upper secondary education; 35 . Upper secondary vocational education; 4. Post-secondary nontertiary education; 45. Post-secondary non-tertiary vocational education; 5. Short-cycle tertiary education; 55. Short-cycle tertiary vocational education; 6. Bachelor's or equivalent level; 7. Master's or equivalent level; 8. Doctoral or equivalent level.

Table 1. Pedagogical technologies/methods used in ESD (number of countries).

\begin{tabular}{|l|c|c|c|c|c|c|c|c|c|c|c|c|c|}
\hline $\begin{array}{c}\text { Technologies } \\
\text { (symbol) }\end{array}$ & \multicolumn{10}{|c|}{ ISCED levels } \\
\cline { 2 - 16 } & 0 & 1 & 2 & 25 & 3 & 35 & 4 & 45 & 5 & 55 & 6 & 7 & 8 \\
\hline CS & 6 & 13 & 18 & 12 & 22 & 14 & 15 & 7 & 11 & 7 & 16 & 17 & 16 \\
\hline D & 14 & 21 & 24 & 13 & 25 & 16 & 15 & 9 & 11 & 7 & 17 & 17 & 17 \\
\hline G & 22 & 25 & 24 & 14 & 23 & 15 & 15 & 8 & 11 & 7 & 15 & 15 & 13 \\
\hline GP & 5 & 9 & 14 & 10 & 15 & 11 & 13 & 6 & 10 & 6 & 17 & 17 & 16 \\
\hline I & 16 & 22 & 23 & 14 & 24 & 17 & 16 & 9 & 11 & 7 & 16 & 16 & 16 \\
\hline M & 8 & 16 & 18 & 10 & 18 & 12 & 11 & 7 & 8 & 7 & 14 & 15 & 15 \\
\hline OL & 23 & 25 & 24 & 14 & 24 & 15 & 16 & 9 & 12 & 7 & 14 & 12 & 11 \\
\hline P & 11 & 12 & 20 & 10 & 21 & 13 & 13 & 7 & 9 & 6 & 12 & 12 & 11 \\
\hline PI & 6 & 10 & 11 & 7 & 19 & 10 & 14 & 7 & 7 & 5 & 16 & 17 & 17 \\
\hline PS & 14 & 20 & 22 & 14 & 24 & 15 & 17 & 9 & 11 & 7 & 17 & 17 & 17 \\
\hline S & 7 & 15 & 17 & 12 & 20 & 15 & 14 & 8 & 11 & 7 & 17 & 16 & 16 \\
\hline SM & 13 & 16 & 22 & 10 & 22 & 13 & 12 & 6 & 9 & 5 & 16 & 16 & 15 \\
\hline VC & 12 & 18 & 20 & 10 & 22 & 13 & 15 & 9 & 11 & 7 & 14 & 15 & 15 \\
\hline WE & 5 & 8 & 10 & 8 & 17 & 14 & 16 & 10 & 11 & 8 & 15 & 14 & 13 \\
\hline
\end{tabular}


The reporting templates have not been submitted by Canada, Cyprus, Denmark, Luxemburgh, Norway, Poland and the Ukraine yet. Italy presented the brief information from the Ministry of Environment, Land and Sea. In accordance to the analysis some countries (Austria, Finland and Switzerland) have not indicated teaching and learning methods used for ESD at the different ISCED levels that are of particular significance in their country. They have not indicated the results in the box of sub-indicator 2.1.3. The detailed information about teaching and learning methods supporting ESD at various levels of formal education is provided in reports of Belarus, Croatian, Estonia, Kyrgyz Republic, Latvia, Montenegro, Romania, Slovenia [5]. All countries except Romania have not inserted additional teaching or learning methods in the blank that are also considered to be key methods in their countries in teaching and learning for sustainable development. Romania added additional inquiry and debates [7].

Analysing the best practices of different countries, it should be noted that in Austria, for example, there are some special student programmes to enhance vision thinking and participation of students like "Future lectures" [8]. In Finland teaching and learning methods are included in the basic educational programmes of schools as well as ESD is based on doing a research [9]. In Switzerland teachers and trainers implement methods, hand-outs, and didactical recommendations on internet data-bases and platforms, or at different teacher education institutions or education publisher houses [10].

The results of ranking of relevant teaching and learning technologies for ESD from the Table 1 according to the frequency of their usage are presented in the Table 2 . We composed this rank from 1 to 14 based on the mentioning of certain technologies in the national implementation reports of 2018 in which ' 1 ' corresponds to "the most frequent method" and '14' as "the least frequent method".

Table 2. Ranking of pedagogical technologies used in ESD.

\begin{tabular}{|c|c|c|c|c|c|c|c|c|c|c|c|c|c|}
\hline \multirow{2}{*}{ Rank } & \multicolumn{13}{|c|}{ ISCED levels } \\
\hline & 0 & 1 & 2 & 25 & 3 & 35 & 4 & 45 & 5 & 55 & 6 & 7 & 8 \\
\hline 1 & OL & PS & OL & \multirow{4}{*}{$\begin{array}{c}\mathrm{PS} \\
\mathrm{S} \\
\mathrm{VC} \\
\mathrm{WE}\end{array}$} & OL & $\mathrm{VC}$ & WE & GP & $\mathrm{S}$ & GP & \multirow{4}{*}{$\begin{array}{c}\text { CS } \\
\text { OL } \\
\text { P } \\
\text { WE }\end{array}$} & \multirow{5}{*}{$\begin{array}{c}\text { WE } \\
\text { OL } \\
\text { CS } \\
\text { M } \\
\text { I }\end{array}$} & \multirow{3}{*}{$\begin{array}{c}\mathrm{I} \\
\mathrm{OL} \\
\mathrm{WE}\end{array}$} \\
\hline 2 & $\mathrm{G}$ & $\mathrm{S}$ & PS & & $\mathrm{S}$ & $\mathrm{OL}$ & GP & WE & $\mathrm{GP}$ & $\mathrm{D}$ & & & \\
\hline 3 & I & $\mathrm{VC}$ & $\mathrm{S}$ & & $\mathrm{VC}$ & $\mathrm{S}$ & $\mathrm{S}$ & $\mathrm{VC}$ & WE & $\mathrm{G}$ & & & \\
\hline 4 & \multirow{2}{*}{$\begin{array}{c}\text { D } \\
\text { PS } \\
\end{array}$} & OL & $\mathrm{VC}$ & & WE & \multirow{3}{*}{$\begin{array}{c}\text { WE } \\
\text { PS } \\
\text { P }\end{array}$} & $\mathrm{VC}$ & $\mathrm{S}$ & $\mathrm{VC}$ & $\mathrm{M}$ & & & \multirow{4}{*}{$\begin{array}{c}\mathrm{M} \\
\mathrm{CS} \\
\mathrm{P} \\
\mathrm{VC}\end{array}$} \\
\hline 5 & & WE & WE & OL & PS & & $\mathrm{OL}$ & OL & OL & $\mathrm{OL}$ & I & & \\
\hline 6 & SM & $\mathrm{D}$ & SM & \multirow{2}{*}{$\begin{array}{c}\mathrm{P} \\
\mathrm{M}\end{array}$} & \multirow{3}{*}{$\begin{array}{c}\mathrm{M} \\
\mathrm{D} \\
\mathrm{SM}\end{array}$} & & PS & D & $\mathrm{D}$ & $\mathrm{P}$ & \multirow{3}{*}{$\begin{array}{c}\mathrm{M} \\
\mathrm{SM} \\
\mathrm{VC} \\
\end{array}$} & \multirow{3}{*}{$\begin{array}{c}\mathrm{P} \\
\mathrm{VC} \\
\mathrm{SM}\end{array}$} & \\
\hline 7 & $\mathrm{VC}$ & $\mathrm{G}$ & $\mathrm{D}$ & & & $\mathrm{M}$ & M & PS & PS & PS & & & \\
\hline 8 & $\mathrm{P}$ & SM & PI & \multirow{5}{*}{$\begin{array}{c}\text { G } \\
\text { D } \\
\text { SM } \\
\text { PI } \\
\text { CS }\end{array}$} & & GP & $\mathrm{D}$ & $\mathrm{P}$ & $\mathrm{P}$ & $S$ & & & SM \\
\hline 9 & $M$ & $\mathrm{P}$ & $G$ & & PI & $\mathrm{D}$ & $\mathrm{P}$ & $\mathrm{G}$ & M & VC & \multirow{2}{*}{$\begin{array}{l}\text { GP } \\
\text { PS }\end{array}$} & \multirow{3}{*}{$\begin{array}{c}\text { PS } \\
\text { D } \\
\text { G } \\
\end{array}$} & D \\
\hline 10 & $\mathrm{~S}$ & $\mathrm{M}$ & $\mathrm{M}$ & & $\mathrm{P}$ & $\mathrm{SM}$ & I & I & CS & WE & & & $\mathrm{G}$ \\
\hline 11 & \multirow{2}{*}{$\begin{array}{l}\text { PI } \\
\text { CS }\end{array}$} & PI & $\mathrm{P}$ & & I & PI & PI & M & PI & CS & \multirow{3}{*}{$\begin{array}{l}\mathrm{S} \\
\mathrm{D} \\
\mathrm{G} \\
\end{array}$} & & PS \\
\hline 12 & & I & $\mathrm{CS}$ & & $\mathrm{G}$ & $G$ & CS & PI & SM & PI & & GP & GP \\
\hline 13 & \multirow{2}{*}{$\begin{array}{c}\text { GP } \\
\text { WE }\end{array}$} & $\mathrm{CS}$ & I & GP & GP & $\mathrm{CS}$ & $\mathrm{SM}$ & \multirow{2}{*}{$\begin{array}{l}\mathrm{CS} \\
\mathrm{SM} \\
\end{array}$} & $\mathrm{G}$ & I & & \multirow{2}{*}{$\begin{array}{c}\text { S } \\
\text { PI }\end{array}$} & \multirow{2}{*}{$\begin{array}{c}\text { S } \\
\text { PI }\end{array}$} \\
\hline 14 & & GP & GP & $\mathrm{I}$ & $\mathrm{CS}$ & I & $\mathrm{G}$ & & I & $\mathrm{SM}$ & PI & & \\
\hline
\end{tabular}

As we can see from the table 2, this applied technologies considerably change from one level of education to another. It must be explained by the age-related psychological features of students and pupils [11]. For example, outdoor learning is a popular technology in the kindergarten that introduce children to the nearest social natural environment as well as games. Although in higher education excursions (together with case studies) also take place, but apparently they are used for more detailed learning of environmental problems and development. However, workplace experience is the most common technology in the level of higher education. It should be noted that discussions, information and communicative technologies, learner-driven projects, problem-solving, surveys, value 
clarification preferably find use in all levels of education. In a small measure philosophical inquiry is in demand and in the high levels its importance is reduced.

Non-formal education related to the ESD is mentioned in the national implementation reports of Hungary, Slovenia, and Estonia 2018. Thus, the sustainability thematic weeks are realized in Hungary [12]. In Romania non-formal education includes study visits, excursions and outdoor learning, thematic projects / activities / workshops / camps, problem-solving, ICT, case studies, debates, volunteering, anti-alcohol /anti-tobacco /antipollution / preventing persons traffic campaigns, exchange of experience, activities dedicated to specific events like ("The European day for citizenship through education", "Earth day", "International day for environment", "The water day", "The tree day", "The world day for animals", "Let's do it!", "Meeting with the employers") [7]. Non-formal education in Slovenian is understood as a particularly strong and relevant frame for SD due to its complexity and local embeddedness. The methodological emphasis is done on the combination of experiential learning (field work and behavioural experiments) and constant reflection through the dialogue with participants based on three types of case: 1. field locations prepared according to several criteria, 2. cases selected and described by participants and 3. written learning materials [13]. In Estonia the programme "Preparation of in-service training curricula and training courses for teachers of formal education and universities and non-formal environmental education professionals" was launched in 2011. The objective of the program was to equip educators and teachers with the competences to implement active learning methods and integrate the cross-curriculum sustainable development topic in their everyday teaching. In-service programs and ESD courses providing initial teachers' education have been prepared and organised. A special in-service training curriculum for formal education teachers and non-formal education professionals was compiled [14].

Data analysis of additional educational technologies and methods presented in the national implementation reports 2018 are of great interest. They are beyond the framework of Table 1. So, problematic and research-oriented learning, creative tasks, networking are specified in the reports of Belarus [15]; in Bosnia and Herzegovina they use research and team teaching [16]; in Croatia - cooperative learning, interdisciplinary and multidisciplinary approach [17]; in Montenegro - activity, problem and process centred approaches, active teaching [18]; in Kyrgyz Republic - a result oriented teaching [19]; in Russian Federation - communicative approach (communication and interaction with adults and peers), cognitive-research approach, competence-based approach [20]. Also heuristic and research methods are used in Slovakia [21] and in Slovenia - meta-cognitive approach, cross-curricular links, learning strategies and approaches, activity days, authentic tasks, method of formative monitoring and evaluation of students' progress, holistic thinking [13].

In May 2018 after splitting the functions of state governing bodies in Russian Ministry of Education and Science between the Ministry of Education and the Ministry of Science and Higher Education the data were presented only for ISCED Levels 0-55. In this regard, in order to obtain a more complete assessment of progress in the field of ESD, we conducted a survey of experts-specialists in the field of ESD.

In the whole it must be admitted that there is a little progress in the field of ESD for Russian Federation by the state of 2019. The summary and self-assessment is estimated as 0.7 according to the scale ( 0 - not started; 1 - in progress; 2 - developing; 3 - completed) that is higher than in $2011(0.5)$, but it is lower than in 2014 [22] and on the indicator 2.1 "Sustainable development key themes are addressed in formal education" - 0.9 (0.8 и 1.1 in the years 2011 and 2014 accordingly). At the same time it is pointed out by the experts that a number of achievements related to ESD have been already developed such as the development of value and philosophical core of ESD content, involving "green" axioms and metaphors in the content, interaction of school subjects and their results in analogy with 
the functional system, designing the "local agenda 21 " at a school level, creating internet consulting platforms and online resources for sustainable development and ESD.

\section{Conclusion}

The pursuit of sustainable development is difficult, and there are no unique solutions [23]. We reviewed various teaching and learning methods and technologies that demonstrate the positive result of their implementation in different levels of education and it is obvious that these forms of outcomes are desired to be applied. It is expected from the teachers to implement a wide range of methods and technologies in the educational process. In our opinion, the most promising educational technologies are the development and implementation of projects by students aimed at practical participation in solving environmental problems. Moreover, the discussions, conceptual and perceptual mapping, simulations, role playing, games, scenarios and modeling, surveys as well as ICT also have essential value. In striving for application of educational technologies for ESD we conclude that it is important to connect SD concept to all areas of human development with a focus on achieving the Sustainable Development Goals accepted in 2015 [24]. Meanwhile, ESD should be considered as a driver of innovative development of the educational system in the whole.

The reported study was funded by Russian Foundation for Basic Research according to the research project № 19-013-00722 “Education for sustainable development in action”.

\section{References}

1. Agenda 21, Report of the United Nations Conference on environment and development, I, 9-479 (1993).

2. Worldwide educating for the future index 2019: from policy to practice (2019).

3. UNECE Strategy for education for sustainable development. URL: http://www.unece.org/fileadmin/DAM/env/documents/2005/cep/ac.13/cep.ac.13.2005. 3.rev.1.e.pdf (2005).

4. A. Ermakov, S. Popov, N. Sabanina, A. Tokarev, D. Ermakov, Eur. Proc. Soc. \& Behav. Sci. LXXI, 61-70 (2019).

5. National implementation reports. URL: http://www.unece.org/env/esd/implementation.html (2018).

6. International standard classification of education ISCED (2012).

7. National implementation report. Romania. URL: http://www.unece.org/env/esd/implementation.html (2018).

8. National implementation report. Austria. URL: http://www.unece.org/env/esd/implementation.html (2018).

9. National implementation report. Finland. URL: http://www.unece.org/env/esd/implementation.html (2018).

10. National implementation report. Switzerland. URL: http://www.unece.org/env/esd/implementation.html (2018).

11. R. Calfee, Handbook of educational psychology, 29-42 (Mahwah, Erlbaum, 2006),

12. National implementation Heport. Hngary. http://www.unece.org/env/esd/implementation.html (2018).

13. National implementation report. Slovenia. URL: http://www.unece.org/env/esd/implementation.html (2018).

14. National implementation report. Estonia. URL: http://www.unece.org/env/esd/implementation.html (2018). 
15. National

implementation

report.

Belarus.

URL:

http://www.unece.org/env/esd/implementation.html (2018).

16. National implementation report. Bosnia and http://www.unece.org/env/esd/implementation.html (2018)

17. National implementation

report.

Herzegovina. URL: http://www .org/env/esd/implem

ementation.html (2018)

18. National implementation

report.

Croatia.

URL: http://www.unece.org/env/esd/implementation.html (2018)

19. National implementation report. Kyrgyz http://www.unece.org/env/esd/implementation.html (2018)

20. National implementation report. Russian http://www.unece.org/env/esd/implementation.html (2018)

21. National implementation report. Montenegro.

URL: http://www.unece.org/env/esd/implementation.html (2018)

22. D. S. Ermakov, Pedagogy, 6, 44-48 (2013)

23. N. Giangrande, R. M. White, M. East, R. Jackson, T. Clarke, M. S. Coste, G. PenhaLopes, Sust. Sci., 11, 2832 (2019)

24. Transforming our world: the 2030 Agenda for sustainable development. URL: http://www.un.org/ga/search/view_doc.asp?symbol= A/RES/70/ 1\&Lang=E (2015) 